\title{
CHAPTER 116
}

\section{TKAPPING UE OUTFALL CUNSTIIUENTS DEHIND SILLS}

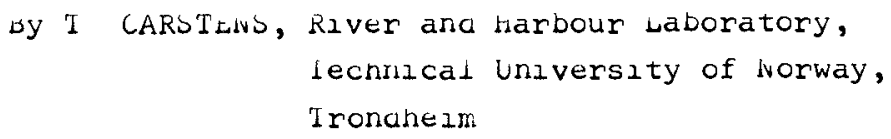

anc A SJUDLRG, nyaraulic Division, Cnalmers Institute of Iechnology, Gotnenburg

\section{ADOTRACI}

Conmunication detween sucn coastal resiplents of waste water as Days and fjords and the ocean is often througn an outlet of small cross section

The combineu effects of a topography with transverse rlages ana a brackisn surface layer creates a rather staglant wody of water. The ridge or sill deflects the traal currents away from the bottom so that only the upper part of the water columin is continually flushea The stabllity of the pycnocline prevents surfacegeneratea turbulence from penetrating auwnwaras, so the turbulerice $2 \mathrm{n}$ the ceep pool is weak.

A scneme nas deen proposea to store the nutrients of sewage outfalls Denzna the sill at vrpdak in the Oslofjord Ine storage capabllity of that fjora was estrmatec for a conservatıve outfall constituent by means of a one almensional asspersion equation from the analysis the galis of deep outfalls through ulffusors collparea witn surface outfalls can de estimated for various perioas between deep water infiows, wnich are observed to occur.

\section{INLRODUCILON}

\section{Topokraphic traps}

The effect of a glven waste water release on the coastal 
enviromient cepenos to a large extent on the coastal morpnology Indentations as well as promontorles tend to create shelterea water bodies with long resiaence times in lárge scàle circulations This tencency is often ennancea by the constricted outlet of many bays ana fjoras

A very efficient kind of constriction is the transverse Dottom riages or silis which are characteristic of the coastal irilets carvea by glaciers ana known as fjoras. A Iongltualnal section of a fjora (Oslofjora) is shown In Flg. $\perp$ several silds alviae the deep fjord into silaller sub-basins of varying size It is olvious tnat tnls type of topography prevents large Docies of water from participating in the nomal movements of coasta 1 waters. In fact, only two significant transport processes seem to exist in the aeep Dasins one, the vertical alffusion, is continuous, while the other is a alscrete process of floud-like iriflows.

Luflcws, Occasional renewal of the water occurs whenevtr the water density at the sill level exceeds the aensity of the vottom water insiae the sill Ine water mass occulylne the Lasin is then forced ufwaras by weislmetric alsplacement, and a conplete or partial rerewal of the basin water takes place witnin a relatively snort perioc of tine The inflowlng volume cepenas on the aensity surpius and its auration and is governea primarily by heteorological variables sucn as wha and atmospherlc pressure (upwelling).

Vertical alffusion Ine density surplus responsidie for tne initial inflow is caused by a salinity surplus and a temperature cefect, comparea witn the overlylng layers Tnus a sailnity gralent is establisnea for a sluw alffusive transport of salt upwares, ana a temperature sraalent for a slullar transport of heat 
downwaras. With time tris alfusion depletes the aensity surplus of the basin water, and the stage is set for a repeat performance, beginning with a new inflow.

Fig 2 snows observed salinities in the two innermost Dasins of the Oslofjora durlind 1962-65, aemonstrating the two processes aescribea above, ana first by GADE (5).

Ine cychocline IId

Ever on open coasts pycnoclines develop near river moutns, tut tne fjoras are particularly prone to stratification, for topograpilc and climatic reasons A regutar feature of any fjord is therefore a pycnocline whicn is usually very stable in the sumrer nalf of tne year

The pycnocline acts as a lia on the deep pool. Vertical circulation that woulu go right to the Dottom in water of constant density, is replacea by a layered flow The shear notion in the pycnocline filters out rost of the norlzontal momentum, so that only very weak flows are set up below the pycnocline

The effect of the aensity graalent on the surfacegeneratea turbulence is equaliy strong. When entralning or eroalng water of higher density, some of the turoulent energy is converted into potential energy in tnis way the pycnocline acts as a sink of turbulence

The comolnea effects of topography ano layering thus create Doales of water witn a rather special flow regline, characterlzed by long residence times and a low exchange witn the surface layer 
Sewage disposal Eenind silis

The sneltered deep basins inslae the sill at Drфbak (Flg 1 ) nave Deen proposed for alsposal of sewage from oslo $(6,7)$. The reasoning is that nutrients can be stored in these basins without causing algal blooms, in contrast to the alsposal through shallow outfalls presently in use. A hign proauction of algae is uncesirable for two reasons, first because it decreases the esthetic and recreational value of the fjord, and seconoly because the organic debris exhausts the oxygen supply at the lower depths.

The usefulness of this scheme ninges on the inflows alscusseu above. A renewal of the deep water must take place before the steady state of maxisum storage has been reached, for which the supply tnrough the sewers equals tne vertical diffusion of a nutrient

\section{A MOUEL FOR CIRCULATION AND DIFFUSION OF DISCHARGLD}

DLWAGL

\section{tartler work}

A nodel for the mixing and the convection in a confined region inauced by a source of buoyancy has been advancec by DAlives and TURiveR (1) veglecting the effect of turvulence in the environment on the rising plume, they obtained asynptotic solutions of the density alstridution valia at large times. The model proposea dy CEDtRWALL (2) for mixing and convection inducea by alschargea sewage follows closely that of DAIivbs and IURNER, Dut is mostly concerned with the alstribution of disposed pollutants 
The simpilfying assumptions made by CLDLRwALL agree well witn those first introduced by the autnors of this paper ( 3 ), nowever, ne neglects tne diffusion of constituents througn the ralocline into the surface layer

\section{Ine present mogel}

A cross stction of the fjorc is snown in Fig 3 The source of the constituent is the effluent outfall at level $z=U$, ana lts strengtn is $Q_{0} c_{0}$, where $Q_{0}$ is the volume flux ana $c_{0}$ the concentration. Because of lts buoyancy, the effluent jet will rise to the level h in the pycnocline rere the censity of the surrounding fluia equals tnat of the jet, and the allutea effluent is trapped in a subnerged fiela referred to as the cloud.

Assumptions In oruer to simplify the analysis we introcuce the following assumptions

1 Inere is no exchange in the deep waters after the complete renewal tnat we cnoose as initial conaltron

2. The density profile is not significantly affectea Dy the induced circulation of sewage

3 The vertical constituent fluy is given by

$$
-D_{z} \frac{G C}{(\sigma z)} A_{z}
$$

wrere $D_{z}$ is the ulffusion coefficient, dc/az the concentration gradient and $A_{z}$ the horizontal area 
4. The effluent is trappeo just below the nalocline and instantaneously spread into a thin layer which will be successively convected and alffused downwarus as new sewage reaches the trapping level

5. Any two scalar components are transported by the same mecnanism. Thus the concentration alstribution of the constituent across the halocline in steacystate condition is just a scaling of the salinity alstribution, or

$$
\frac{a c}{d z}+=\frac{\Delta c}{\Delta s}\left[\frac{d s}{d z}\right]_{h}+
$$

where $\Delta c$ ara $\Delta s$ are the alfference in concentration of the constituent. $z=n$ is the trapping level ano $\mathrm{h}^{+}$refers to "just aoove" ana accoraingly $\mathrm{n}^{-}$to "Just below" The tune lag to reach staoy-state from inltial conditions is of the orcer of one week and may be neglected ( 3 ). The vertical constituent flux upwaras to the surface layer is then given by

$$
-\left[D_{z} \frac{I}{\Delta s} \cdot \frac{\delta s}{\delta z} \cdot A_{z}\right]_{h}+c(h, t)=Q_{v} c(h, t)(3)
$$

For simplicity the concentration of the constituent in the surface is assumeu to be zero

6. The amount of sewage alscharged to the fjord during a year is small comparea with the fjord water avaliable for dilution.

7. Ine freshwater runoff is sufflclent to malntaln a aensity stratification, Lut does not inauce appreciadle upwara entrainment (CARSTens (4)) 


\section{The aispersion equation}

The convection and mixing within the trapped cloud outside the plume is now described by the one dimenslonal alspersion model

$$
\frac{\delta c}{\delta t}-U \frac{\delta c}{\delta z}=\frac{\partial}{\delta z}\left(D_{z} \frac{\delta c}{\delta z}\right)
$$

where $U=Q(z) / A(z)$ is the Induced convective velocity and $Q(z)$ the plume flow rate at level $z$. Eq. (4) can be solved numerically together with the continulty equation for the constituent within the cloud

$$
\begin{aligned}
& Q_{0} c_{0}+\int_{0}^{z} c a Q-Q_{v} c(h, t)+U(z) A_{z}(z) c(z, t) \\
& -D_{z} \frac{\delta C}{\delta z} A_{z}=\int_{z}^{h} \frac{\delta c}{\delta t} A_{z} d z
\end{aligned}
$$

which for $z=n$ has the following form

$$
\begin{aligned}
& Q_{0} c_{0}+\int_{0}^{z} c d Q-Q_{v} c(h, t)+U(z) A_{z}(z) c(z, t) \\
& -\left[D_{z} \frac{\delta c(h, t)}{\delta z} A_{z}\right]_{h}=0
\end{aligned}
$$

Ine first term is the source, the second term accounts for the recirculation of the constituent, and the thira term is the constituent flux into the surface layer. The fourth and the fifth terms, respectively, represent the convective ana the diffusive downward flux.

A straight forward numerical treatment of tqs. (4) and (6) is not feasible at present. We have not completely solvea the problem of supporting convenient mathematical 
models with sound physical arguments. We shall, however, use Eqs. (5) and (6) to estimate the time history $c(h, t)$ of the cloud concentration at the trapping level. we feel our solutions for small and for large values of $t$ are acceptable, but we do not yet have a solution for intermealate values of $t$.

Solution for small $t$ For small $t$ the thlckness of the cloud is small compared with the neight $h$. Hence, the recirculation of the constituent may de neglected

$$
\int_{0}^{n} \operatorname{caQ} \approx 0, \text { and } U(h) \cdot A_{2}(h) \approx Q_{0} S_{0}
$$

where $s_{0}$ is the dilution at the trapping level.

For smill $t$ we may also assune the vertical distrioution of the constituent concentration above the trapping level to be a mirror image of tnat below. Tnus, the upward diffusive flux equals the downward flux ana

$$
-\left[D_{z} \frac{\delta c(z, t)}{\delta z} A_{z}\right]_{n^{-}} \cdot c(h, t)=Q_{v} c(h, t)
$$

With these assumptions Eq ( 6 ) has the solution

$$
\frac{c(n, t)}{c_{0}}=\frac{Q_{0}}{(I+\alpha) Q_{v}+Q_{0} S_{0}}
$$

where $\alpha \approx 2$ for small $t$ As the concentration in the surface layer is assumed to be constant $=0$, a decreases witn growing t. Flg. 4 shows Eq. (9) for a particular case in tre oslofjora.

Solution for large $t$. The effluent cloud is successively convected and diffused aownwaras. In order to get a rough estimate of the transport velocity we consiaer only the convection and neglect the diffusion. We then nave to fina the rate of advance of the first 
front. If we take $U_{0}$ as the front velocity and $z_{0}$ as the front level, it follows from continusty tnat

$$
U_{0}=\frac{Q\left(z_{0}\right)}{A_{z}\left(z_{0}\right)}
$$

and the travel time $T$ is given by

$$
T=\int_{z_{0}}^{h} \frac{d z}{U_{0}}=\int_{z_{0}}^{h} \frac{A_{z}}{Q} d z
$$

For a particular diffusor arrangement $\left(S_{0}=50\right)$ in the oslofjord with $Q_{0}=10 \mathrm{~m}^{3} / \mathrm{s}$ and $h=60$, T required for $z_{0}=0.1 \mathrm{~h}$ may be calculated to about 14 months

For t>14 months most of the deep water has recycled once anc the effluent may be assumed to be approximately uniformly mixed into the deep water In this case of ldeal mixing we have

$$
\begin{aligned}
& c(h, t)=c(z, t)=c(t) \\
& \int_{0}^{h} \frac{\delta c}{\delta t} A_{z} a z=\frac{\delta c}{\delta t} \int_{0}^{h} A_{z} d z=\frac{\delta c}{\delta t} V
\end{aligned}
$$

where $V$ is the deep water volume between the levels $z=0$ and $z=n$. We also have $U(0)=0$. With $z=0 \mathrm{kq}$. (5) then takes the form

$$
Q_{0} c_{0}-Q_{v} c(t)=\frac{\partial c}{\delta t} V
$$

which has the solution

$$
\begin{aligned}
& \text { solution } \\
& c_{0}
\end{aligned}=\frac{Q_{0}}{Q_{v}}\left(1-e^{-\frac{Q_{v} t}{v}}\right)
$$

Flg. 4 shows Eq. (14) for a particular case in the Oslof jora

$$
Q_{0}=10 \mathrm{~m}^{3} / \mathrm{s}, S_{0}=50, D_{z}=3 \cdot 10^{-5} \mathrm{~m}^{2} / \mathrm{s}
$$




$$
\begin{aligned}
& \frac{l}{\Delta s} \frac{d s}{d z}=0,15 / m, A_{z}(h)=1,1 \cdot 10^{8} \mathrm{~m}^{2}, \\
& V=4,2 \cdot 10^{9} \mathrm{~m}^{3}
\end{aligned}
$$

\section{CONCLUSIONS}

A transverse ridge or sill on the bottom shelters the water mass below the sill depth from tidal flushing. A pycnocline proviaes adaltional sheltering from surface-generated turbulence, and so the body of water behind a sill and below a pycnocline is characterized by long residence times.

The Dullaup of the concentration of an outfall constituent released in such a stagnant body of water was investrgated for the special case of the Oslofjord, based on a set of assumptions leading to a general onealmensional dispersion equation.

Solutions were obtalned for small and large periods of constituent release, respectively. The solution for small $t$ assumes a rapld horlzontal spreaa compared with the vertical transport The solution for large $t$ assumes laeal mixing. A tentative "probable curve" has been inserted for intermediate tımes.

From the analysis the gains of deep outfalls through diffusors compared with surface outfalls can be estimated for varlous perlods between deepwater inflows. 


\section{RLELRLIVCES}

1. BAINES, W.D. and TURNER, J.S. Turbulent buoyant Convection from a Source in a Confined Region. - J. Fluzd Mech. Vol. 37 Part I, 1969

2. CEDERWALL, $K$. The Oslo Fjord - A Model for Circulation and Diffusion of Discharged Sewage. - Technlcal Memorandum 70-I. W.M. Keck Laboratory of hydraulics and Water Resources, Cal. Inst. of Techn. 1970.

3 CARSTENS, T. and SJфbERG, A. Osiofjorden II An evaluation of sewage outfalis inside Drøbak. - NIVA, Oslo 1969. (In Norweglan).

4 CARSTENS, T. Turbulent diffusion and entrainment in two-layer flow - ASCE VWI, 77-104, Feb 1970 .

5. GADE, H. Oslofjordens hydrografl. Delrapport nr. 2. - NIVA, Osio 1967. (In Norweglan).

6. The Oslofjord and its poliution problems Samierapport I. NIVA, Oslo, 1968. (In Norweglan).

7. The OsLofjord and 1 ts poliution problems Samlerapport II. INIVA, OsIo, 1970. (In Norweglan). 

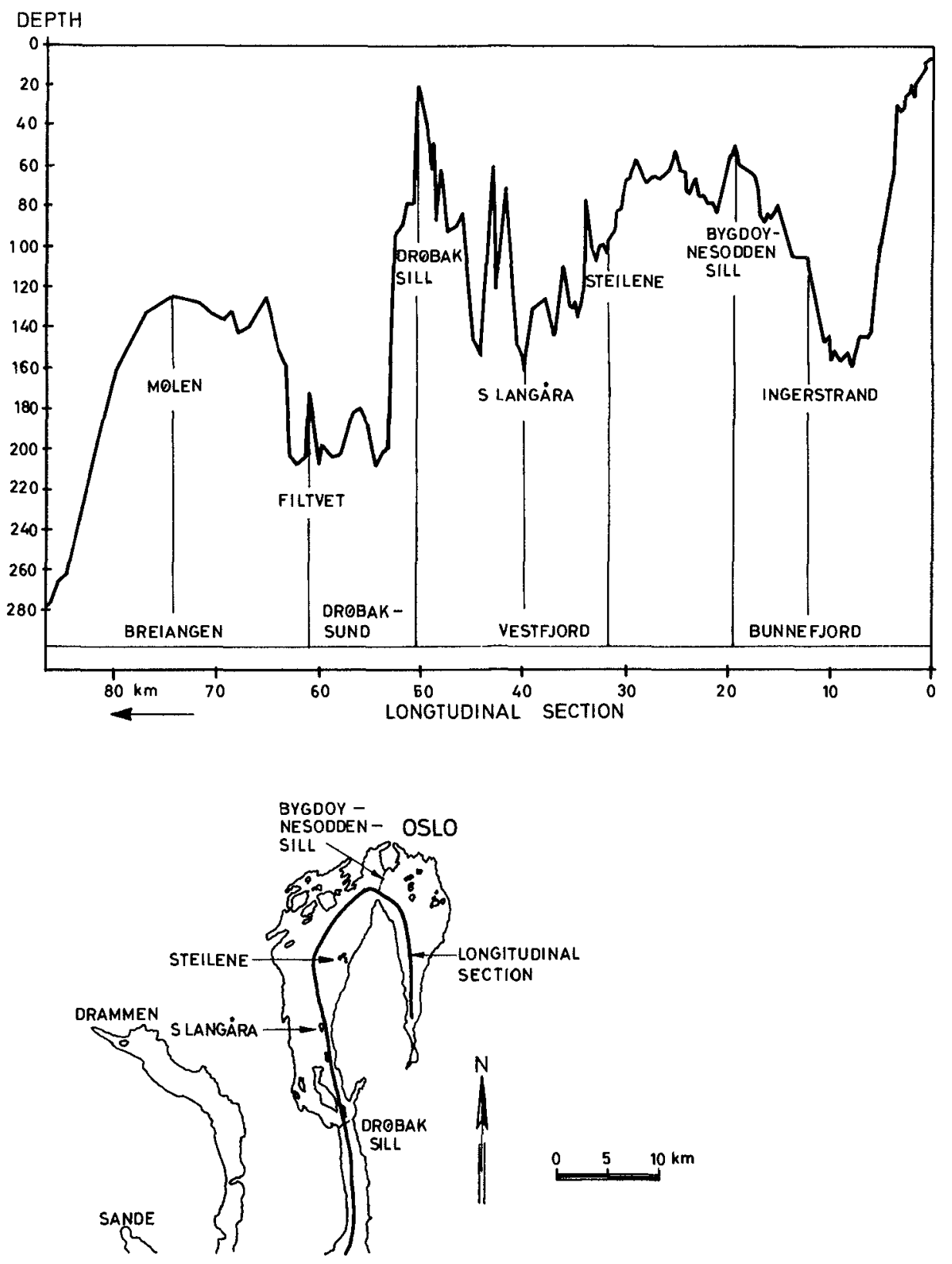

FIG 1 THE OSLOFJORD, PLAN AND SECTION 


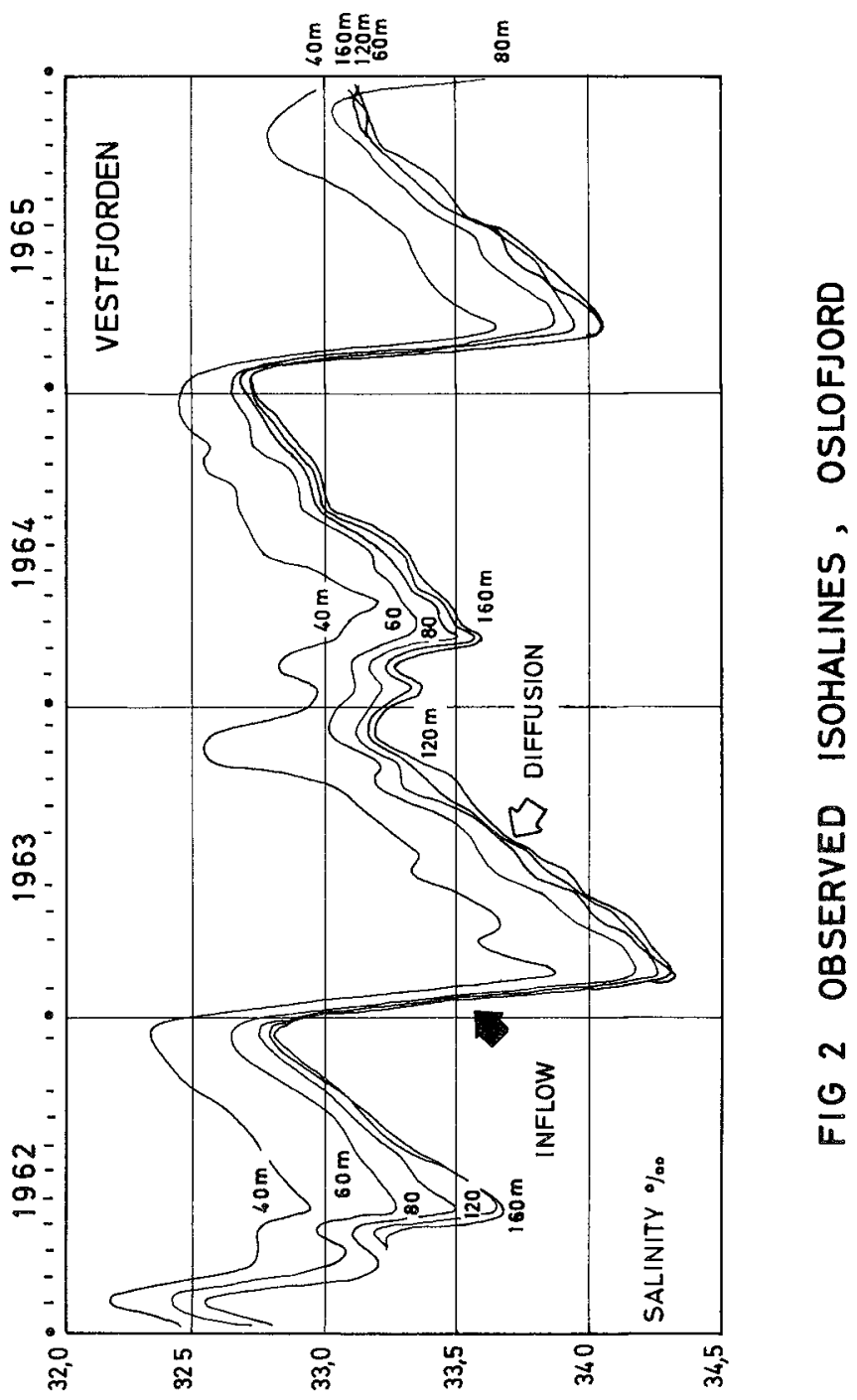




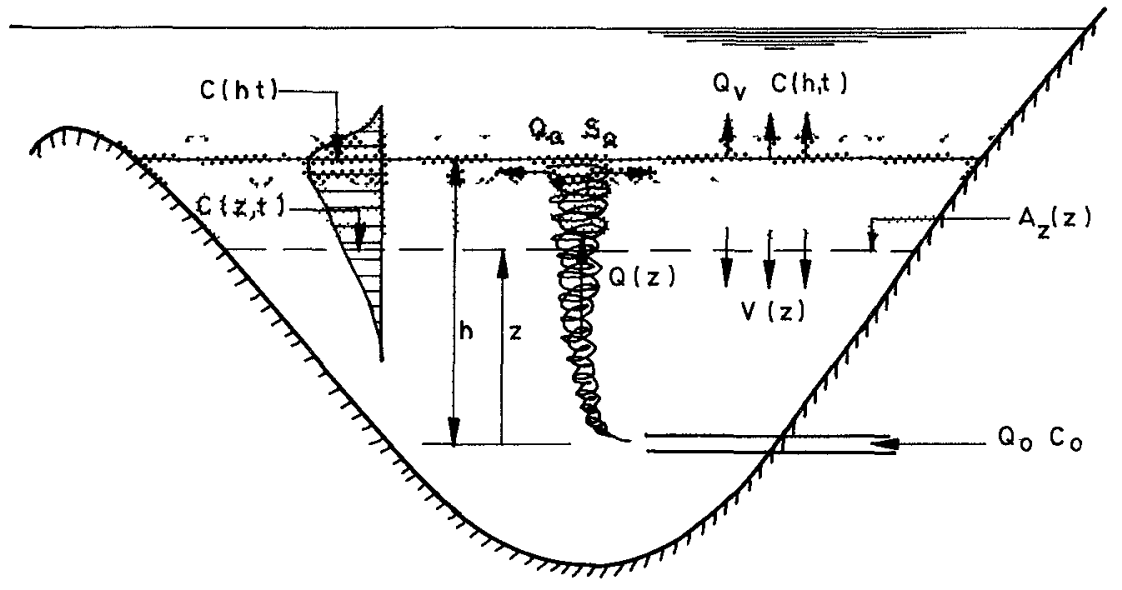

FIG 3 SCHEMATIC OF A SECTION THROUGH THE FJORD

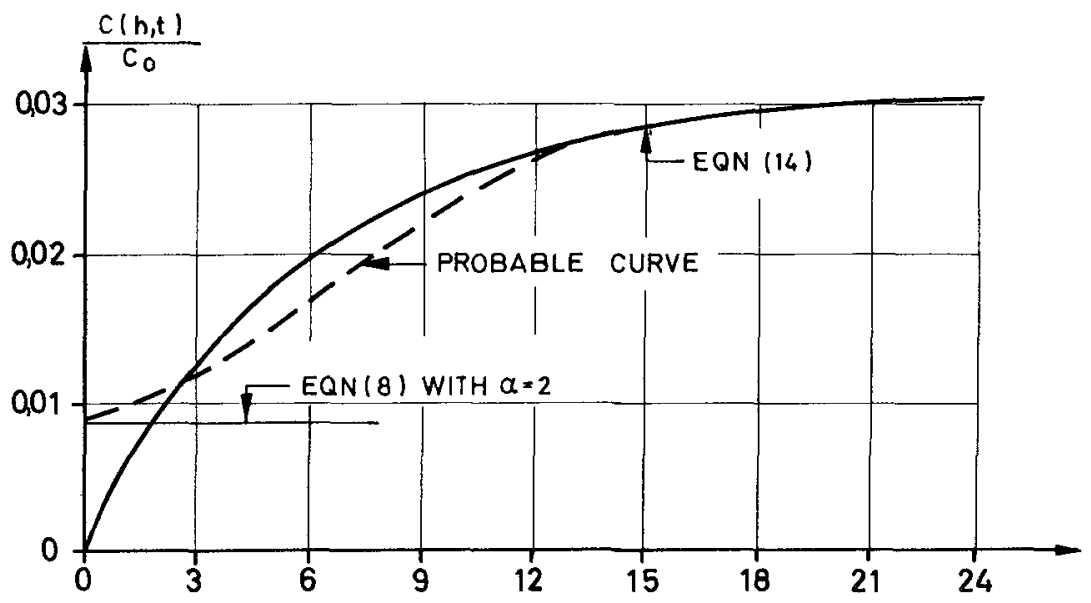

FIG 4 TIME HISTORY OF CLOUD CONCENTRATION AT TRAPPING LEVEL (OSLOFJORD) 